\title{
Research on the Collocation of Natural Casings
}

\author{
Qiming Feng ${ }^{1 *}$, Suping Qian ${ }^{2}$ \\ ${ }^{1}$ Wuxi Institute of Commerce, Department of Mathematics, 214153, Wuxi, Jiangsu, China \\ ${ }^{2}$ Wuxi Institute of Commerce, School of Accounting and Finance, 214153, Wuxi, Jiangsu, China
}

\begin{abstract}
This paper discusses the reasonable collocation of natural casings. Through the analysis and research of the problems, the optimal model of the bundle number of assembled products is established. For this multi-objective optimization problem, the finished products are sorted according to the length from long to short, and then the method of hierarchical optimization algorithm is used to solve the problem. Finally, the empirical analysis of the given actual data is carried out. It provides an important idea for the formulation of the collocation scheme, and the solution of this problem can be extended to other aspects of production.
\end{abstract}

\section{Introduction}

The natural casings are the animal tissues which are dried or salted on the preserved parts of the large intestine, small intestine and esophagus of healthy livestock after special processing.[1] According to different processing methods, natural casings are divided into dry casings and salted casings. The dried casings include dried pig casings, dried sheep casings and dried cattle casings, and the main types of salted casings are basically the same as dry casings. The casings are mainly used as coats for filling sausages, etc. The production of natural casings is a traditional industry in China, and its export volume occupies the first place in the world. After cleaning and finishing, the casings are divided into small sections with different lengths as raw materials, and then enter the assembly process. The traditional production method is that workers calculate the length of raw materials while measuring them, and assemble the raw materials into finished products (in bundle) according to the specified number and total length.[2]

Raw materials are divided into different grades according to their length, and the difference between the two grades is usually 0.5 meters. For example, 3-3.4 meters is calculated as 3 meters, 3.5-3.9 meters is calculated as 3.5 meters, and the rest is calculated as such. There are three specifications of common finished products. Table 1 shows the minimum length, maximum length, total length and total number of raw materials for each specification of finished products. Here, the symbol $\infty$ indicates that there is no upper limit, but in practice, the length is less than 26 meters.

Table 1. The specifications of finished products

\begin{tabular}{|c|c|c|c|c|}
\hline Specification & $\begin{array}{c}\text { Minimum length } \\
\text { (in meter) }\end{array}$ & $\begin{array}{c}\text { Maximum length } \\
\text { (in meter) }\end{array}$ & $\begin{array}{c}\text { Total number } \\
\text { (in bundle) }\end{array}$ & $\begin{array}{c}\text { Total length } \\
\text { (in meter) }\end{array}$ \\
\hline I & 3 & 6.5 & 20 & 89 \\
\hline II & 7 & 13.5 & 8 & 89 \\
\hline III & 14 & $\infty$ & 5 & 89 \\
\hline
\end{tabular}

In order to improve production efficiency, the company plans to change the assembly process. On the basis of measuring all raw materials and establishing a raw material list, a collocation scheme will be established according to the specifications of finished products, and in this way, the workers only need to assemble the finished products according to this scheme. Table 2 shows the description of a batch of raw materials.

The company has the following specific requirements for the collocation scheme:
(1) For a given batch of raw materials, it is better to match the scheme with more bundles of finished products.

(2) For the scheme with the same number of finished bundles, if the bundles with the longer minimum length are more, and the corresponding scheme is better.

(3) In order to improve the utilization rate of raw materials, the total length is allowed to have an error of \pm 0.5 meters, and the total number is allowed to be one section less than the standard.

(4) If there is surplus raw material corresponding to a certain type, it can be degraded for use. For example,

* Corresponding author: feng_qiming@163.com 
the raw materials with a length of 14 meters can be bundled with those with a length of 7-13.5 meters, and the finished products belong to the specification II.
(5) In order to keep food fresh, it is required to produce a scheme within 30 minutes.[3]

Table 2. The description of a batch of raw materials

\begin{tabular}{|c|c|c|c|c|c|c|c|c|}
\hline Length & $3-3.4$ & $3.5-3.9$ & $4-4.4$ & $4.5-4.9$ & $5-5.4$ & $5.5-5.9$ & $6-6.4$ & $6.5-6.9$ \\
\hline Number & 43 & 59 & 39 & 41 & 27 & 28 & 34 & 21 \\
\hline Length & $7-7.4$ & $7.5-7.9$ & $8-8.4$ & $8.5-8.9$ & $9-9.4$ & $9.5-9.9$ & $10-10.4$ & $10.5-10.9$ \\
\hline Number & 24 & 24 & 20 & 25 & 21 & 23 & 21 & 18 \\
\hline Length & $11-11.4$ & $11.5-11.9$ & $12-12.4$ & $12.5-12.9$ & $13-13.4$ & $13.5-13.9$ & $14-14.4$ & $14.5-14.9$ \\
\hline Number & 31 & 23 & 22 & 59 & 18 & 25 & 35 & 29 \\
\hline Length & $15-15.4$ & $15.5-15.9$ & $16-16.4$ & $16.5-16.9$ & $17-17.4$ & $17.5-17.9$ & $18-18.4$ & $18.5-18.9$ \\
\hline Number & 30 & 42 & 28 & 42 & 45 & 49 & 50 & 64 \\
\hline Length & $19-19.4$ & $19.5-19.9$ & $20-20.4$ & $20.5-20.9$ & $21-21.4$ & $21.5-21.9$ & $22-22.4$ & $22.5-22.9$ \\
\hline Number & 52 & 63 & 49 & 35 & 27 & 16 & 12 & 2 \\
\hline Length & $23-23.4$ & $23.5-23.9$ & $24-24.4$ & $24.5-24.9$ & $25-25.4$ & $25.5-25.9$ & & \\
\hline Number & 0 & 6 & 0 & 0 & 0 & 1 & & \\
\hline
\end{tabular}

\section{Problem analysis}

Based on the analysis of the given data and requirements, it is concluded that the problem can be transformed into a dual objective optimization problem. The first goal is to maximize the bundles of finished products, and the second is when the number of bundles in two schemes is the same, the scheme with the longer minimum length of finished products is better. According to the characteristics of practical problems, we can use hierarchical algorithms to solve the problem. The whole optimization scheme can be completed in three steps. Firstly, the optimal collocation scheme for the raw materials belonging to the third type is given, and the remaining raw materials move down to the second type before matching. Secondly, the optimal collocation scheme for the raw materials belonging to the second type is given, and the remaining raw materials move down to the first type before matching. Finally, the raw materials belonging to the first type are optimized and the collocation scheme is given.[4]

For the optimized collocation of each type of raw materials, its objectives and constraints are basically the same. As long as the optimization model in one specification is established, it can be translated to the other specifications of optimization process.[5]

\subsection{Symbol explanation}

In order to establish the mathematical model, some necessary symbols and their meanings are given first.

1) $n$ represents the total number of raw materials of a certain type.

2) $m$ represents the number of each bundle in the finished product of a certain specification.

3) $\quad l$ represents the total length of each bundle of finished products.

4) $\quad l_{i}(i=1,2, \cdots, n)$ represents the length of raw materials.

5) $y_{i}(i=1,2, \cdots, n), y_{i}=1$ indicates that the ith bundle is put into raw material, otherwise, it is empty.

6) $\quad x_{i j}(i=1,2, \cdots, n, j=1,2, \cdots, n), x_{i j}=1$ indicates that the $j$-th raw material is put into the $i$-th bundle, otherwise, it indicates that it is not put into the $i$ th bundle.

\subsection{Data preprocessing}

There are three specifications of finished products. According to the specification of finished products and the description of raw materials, the raw materials are also divided into three types. The calculated length of raw materials after grading is as follows.

\section{Model establishment}


Table 3. The calculated length of the first type of raw materials

\begin{tabular}{|c|c|c|c|c|c|c|c|c|}
\hline length & $\begin{array}{c}11, \ldots, \\
143\end{array}$ & $\begin{array}{c}144, \ldots, \\
1102\end{array}$ & $\begin{array}{c}1103, \ldots, \\
1141\end{array}$ & $\begin{array}{c}1142, \ldots, \\
1182\end{array}$ & $\begin{array}{c}1183, \ldots, \\
1209\end{array}$ & $\begin{array}{c}1210, \ldots, \\
1237\end{array}$ & $\begin{array}{c}1238, \ldots, \\
1271\end{array}$ & $\begin{array}{c}1272, \ldots, \\
1292\end{array}$ \\
\hline meter & 3 & 3.5 & 4 & 4.5 & 5 & 5.5 & 6 & 6.5 \\
\hline
\end{tabular}

Table 4. The calculated length of the second type of raw materials

\begin{tabular}{|c|c|c|c|c|c|c|c|c|}
\hline length & $\begin{array}{c}11, \ldots, \\
124\end{array}$ & $\begin{array}{c}125, \ldots, \\
148\end{array}$ & $\begin{array}{c}149, \ldots, \\
168\end{array}$ & $\begin{array}{c}169, \ldots, \\
193\end{array}$ & $\begin{array}{c}194, \ldots, \\
1114\end{array}$ & $\begin{array}{c}1115, \ldots, \\
1137\end{array}$ & $\begin{array}{c}1138, \ldots, \\
1158\end{array}$ & $\begin{array}{c}1159, \ldots, \\
1176\end{array}$ \\
\hline meter & 7 & 7.5 & 8 & 8.5 & 9 & 9.5 & 10 & 10.5 \\
\hline length & $\begin{array}{c}1177, \ldots, \\
1207\end{array}$ & $\begin{array}{c}1208, \ldots, \\
1230\end{array}$ & $\begin{array}{c}1231, \ldots, \\
1252\end{array}$ & $\begin{array}{c}1253, \ldots, \\
1311\end{array}$ & $\begin{array}{c}1312, \ldots, \\
1329\end{array}$ & $\begin{array}{c}1330, \ldots, \\
1354\end{array}$ & & \\
\hline meter & 11 & 11.5 & 12 & 12.5 & 13 & 13.5 & & \\
\hline
\end{tabular}

Table 5. The calculated length of the third type of raw materials

\begin{tabular}{|c|c|c|c|c|c|c|c|c|c|c|}
\hline length & $\begin{array}{c}11, \ldots, \\
135\end{array}$ & $\begin{array}{c}136, \ldots \\
164\end{array}$ & $\begin{array}{c}165, \ldots \\
194\end{array}$ & $\begin{array}{c}195, \ldots \\
1136\end{array}$ & $\begin{array}{c}1137, \ldots \\
1164\end{array}$ & $\begin{array}{c}1165, \ldots \\
1206\end{array}$ & $\begin{array}{c}1207, \ldots \\
1251\end{array}$ & $\begin{array}{c}1252, \ldots \\
1300\end{array}$ & $\begin{array}{c}1301, \ldots \\
1350\end{array}$ & $\begin{array}{c}1351, \ldots \\
1414\end{array}$ \\
\hline meter & 14 & 14.5 & 15 & 15.5 & 16 & 16.5 & 17 & 17.5 & 18 & 18.5 \\
\hline length & $\begin{array}{c}1415, \ldots \\
1466\end{array}$ & $\begin{array}{c}1467, \ldots \\
1529\end{array}$ & $\begin{array}{c}1530, \ldots \\
1578\end{array}$ & $\begin{array}{c}1579, \ldots \\
1613\end{array}$ & $\begin{array}{c}1614, \ldots \\
1640\end{array}$ & $\begin{array}{c}1641, \ldots \\
1656\end{array}$ & $\begin{array}{c}\mathrm{L} 657, \ldots, \\
\mathrm{L} 668\end{array}$ & $\begin{array}{c}\mathrm{L} 669, \ldots \\
1670\end{array}$ & $\begin{array}{c}1671, \ldots \\
1676\end{array}$ & 1677 \\
\hline meter & 19 & 19.5 & 20 & 20.5 & 21 & 21.5 & 22 & 22.5 & 23.5 & 25.5 \\
\hline
\end{tabular}

\section{3 mathematical model}

This is a combinatorial optimization problem, the mathematical representation of this optimization problem is as follows.

$$
\begin{aligned}
& \min n-\sum_{i=1}^{n} y_{i} \\
& \text { s.t. } \quad(l-0.5) y_{i} \leq \sum_{j=1}^{n} l_{j} x_{i j} \leq(l+0.5) y_{i} \quad i \in D=\{1,2, \cdots, n\} \\
& \sum_{i=1}^{n} x_{i j}=1 \quad j \in D \\
& m-1 \leq \sum_{j=1}^{n} x_{i j} \leq m \quad j \in D \\
& \sum_{i=1}^{n} x_{i j}=1 \quad j \in D \\
& x_{i j}=1 \text { or } 0 \quad i, j \in D \\
& y_{i}=1 \text { or } 0 \quad i \in D
\end{aligned}
$$

This optimization problem is NP-Completeness. At present, only some heuristic algorithms are proposed for the problem, but there is no algorithm that can find the optimal solution in polynomial time. Most heuristic algorithms are based on greedy methods and some simple rules, such as next-fit heuristic (NF), first-fit heuristic (FF), best-fit heuristic (BF). Garey and Johnson point out that the result of simple heuristic algorithm can be no less than (but not better than) the optimal solution multiplied by a relatively small coefficient. [6]

In order to achieve the second goal, that is, when the number of bundles in two schemes is the same, the scheme with the longer minimum length of finished products is better. The raw materials are arranged in descending order of length, and then calculated by NF, FF, or BF algorithm.
These corresponding algorithms are called next fit decreasing algorithm (NFD), first fit decreasing algorithm (FFD), and best fit decreasing algorithm (BFD). The time complexity of these algorithms is $\mathrm{O}(\mathrm{n} \log n)$. [7]

\subsection{Calculation results}

Some types of raw materials can be degraded if they are surplus. Therefore, the optimal collocation scheme of raw materials belonging to the third type is given first, the remaining raw materials are put into the second type of raw materials, and then the optimal collocation scheme of raw materials belonging to the second type is given. By using the same method, the raw materials belonging to the first type can be optimized, so that the whole optimization 
scheme can be obtained. The calculation results are as follows.

Table 6. The calculation results

\begin{tabular}{|c|c|c|}
\hline Specification & Optimal number of bundles & Quantity of remaining raw materials \\
\hline I & 17 & 17 \\
\hline II & 40 & 18 \\
\hline III & 135 & 7 \\
\hline Total & 192 & \\
\hline
\end{tabular}

It can be seen from the above table that the optimal number of finished products of specification $\mathrm{I}$ is 17 bundles, the specification II is 40 bundles, the specification III is 135 bundles, and the optimal total number is 192 bundles. Finally, there are seven sections of raw material remaining.

\section{Conclusion}

The production of natural casings is a traditional industry in China, but the efficiency of traditional production mode is relatively low. To solve this problem, we find a more efficient way to solve this problem by establishing optimization mathematical model, and that enterprises can get higher profits. There are tens of thousands of ways to match the finished natural casings, therefore, it is necessary to adopt the hierarchical optimization algorithm to save time, but the solution obtained by this method is not the global optimal solution. In a word, this algorithm is simple, easy to program, fast in operation and good in solution.

\section{Acknowledgments}

This paper is supported by the Famous Teacher Project of Wuxi Institute of Commerce.

\section{References}

1. General Administration of Quality Supervision Inspection and Quarantine of the People's Republic of China, National Standardization Management Committee.(2007) GB / T 20572-2006 HACCP Application Specification for Natural Casing Production. [M] China Standards Press. Beijing.

2. Zhu J. L. (2009) Processing Guide for Natural Casings. China Measurement Press. Beijing.

3. 2011 question D. National Mathematical Modeling Competition for College Students. http://www.mcm.edu.cn/html_cn/node/a1ffc4c5587 c8a6f96eacefb8dbcc34e.html.

4. Cai L. , Yu L. (2019) Resource Allocation Algorithm of Big Data Based on Genetic Algorithm [ J ] . Journal of Chongqing University of Technology( Natural Science) 33(4) : $134-140$.

5. Zhang S. J. (2017)Research on Multidimensional Packing Problem Based on Genetic Algorithm.[J] Electronic World.23(10) :81-82.

6. Garey, M. and D. Johnson, (1979)Computers and Intractability: A Guide to the Theory of NPCompleteness, W.H. Freeman, New York.

7. Liu D. Y, Wei F.H, Gao N. Liu H, Xie W. J. (2017)Research Progress of Influencing Factors and Countermeasures for the Development of Natural Casings Industry in China. [J] Meat Research.31(1):42-47. 